\title{
Prevalence of diastolic dysfunction according to the diagnostic guidelines of 2009 and 2016: Relationship with non-invasive hemodynamic assessment
}

\author{
Prevalencia de disfunción diastólica de acuerdo con las guías diagnósticas de 2009 y \\ 2016. Relación con la valoración hemodinámica no invasiva \\ Adrián Carlessi*, Leonel Perello, Evangelina Garello, and Carlos Valli \\ Department of Cardiology, Department of Echocardiography, Sanatorio San Gerónimo, Santa Fe, Argentina
}

\begin{abstract}
Objectives: The objectives of the study were to assess the prevalence of developmental disabilities (DD) according to the criteria of the 2009 and 2016 guidelines and its association with systemic arterial compliance (DAS) and peripheral vascular resistance (RVP). Material and methods: $A$ total of 306 patients aged $\geq 40$ years, with ejection fraction $\geq 50 \%$ were analyzed. It was estimated in all DAS and RVP. Results: The prevalence of DD was $32.7 \%$ and $22.9 \%$ according to the 2009 and 2016 guidelines, respectively $(p \leq 0.0001)$. Patients with $D D$ according to the 2009 guideline had a lower average of $D A S$ than those with normal function ( $p=0.0001)$. Similar with the 2016 guide $(p=0.0007)$. The presence of $D D$ according to the 2009 and 2016 guideline showed higher RVP values than normal values $(p=0.005$ and $p=0.018$, respectively). The $D D$ according to both guidelines was a predictor, in the univariate analysis, of $D A S<0.60 \mathrm{ml} . \mathrm{mmHg}^{-1}$ and $R V P>1400 \mathrm{mmHg}$. min. $l^{-1}$. The $D D$ according to the 2009 guideline persisted as an independent predictor, in the multivariate analysis, of RVP $>1400 \mathrm{mmHg}$. min..$^{-1}$ Conclusion: The 2016 guide decreases the prevalence of DD. The DD, both from the 2009 and 2106 guidelines, were univariate predictors of DAS $<0.60 \mathrm{ml} . \mathrm{mmHg}^{-1}$ and RVP $>1400 \mathrm{mmHg} \cdot \mathrm{min}^{-1} \mathrm{I}^{-1}$. The $D D$, according to the 2009 guide, was an independent predictor of RVP $>1400 \mathrm{mmHg} \cdot \mathrm{min}^{-l^{-1}}$.
\end{abstract}

Key words: Diastole. Hemodynamics. Doppler. Echocardiography.

\section{Resumen}

Objetivos: Evaluar la prevalencia de DD de acuerdo con los criterios de las guías del 2009 y 2016, y su relación con la distensibilidad arterial sistémica (DAS) y la resistencia vascular periférica (RVP). Material y métodos: Se analizó a 306 pacientes $\geq 40$ años de edad, con fracción de expulsión $\geq 50 \%$. Se calcularon en todos DAS y RVP. Resultados: La prevalencia de DD fue de $32.7 \%$ y 22.9\% según las guías de 2009 y 2016, respectivamente $(p=<0.0001)$. De acuerdo con las guías del 2009 , los pacientes con DD presentaron una media de DAS menor que aquéllos con función normal ( $p=0.0001)$, de modo similar a las guías del 2016 ( $p=0.0007)$. La DD, según las guías de 2009 y 2016, mostró valores más altos de RVP que los normales $\left(p=0.005\right.$ y $p=0.018$, respectivamente). Asimismo, la DD fue predictora, en el análisis univariado, de DAS $<0.60 \mathrm{ml} . \mathrm{mm} \mathrm{Hg}^{1}$

Correspondence:

*Adrián Carlessi

E-mail: adriancarlessi@gmail.com license (http://creativecommons.org/licenses/by-nc-nd/4.0/).

Date of reception: 11-09-2019

Date of acceptance: 24-03-2020

DOI: 10.24875/ACME.M20000151
Available online: 02-03-2021

Arch Cardiol Mex (Eng). 2020;90(4):385-390 www.archivoscardiologia.com 
y RVP > 1,400 mmHg.min..$^{-1}$ según ambas guías. En el análisis multivariado, la $D D$, de acuerdo con las guías del 2009, persistió como predictor independiente de RVP > 1,400 mmHg.min. $I^{1}$. Conclusión: Las guías del 2016 reducen la prevalencia de DD. Ésta, tanto en las guías del 2009 como en las del 2106, fue predictor univariado de $D A S<0.60 \mathrm{ml} . \mathrm{mmHg}^{1}$ y $R V P>1,400 \mathrm{mmHg}$. min. $I^{1}$. La DD, de acuerdo con las guías de 2009, resultó predictora independiente de RVP $>1,400 \mathrm{mmHg} \cdot \mathrm{min} . \mathrm{I}^{-1}$.

Palabras clave: Diástole. Hemodinamia. Doppler. Ecocardiografía.

\section{Introduction}

Diastole is the period of the cardiac cycle whose alteration and consequent dysfunction are critical and necessary for the development of heart failure, especially in patients with preserved systolic function ${ }^{1}$, which has implications for prognosis ${ }^{2}$. Non-invasive diastolic function study, through echocardiography, has evolved overtime, and the values and parameters that are used have varied, according to expert guidelines. In 2016, the American Society of Echocardiography (ASE) and the European Association of Cardiovascular Imaging (EACVI) recommendations were published ${ }^{3}$; these guidelines made an emphasis on the simplification of the parameters to be used and were based on the most feasible and reproducible. In addition, they differed from the 2009 ASE and the European Association of Echocardiography (EAE) recommendations ${ }^{4}$, which use more complex algorithms and parameters.

Non-invasive assessment of hemodynamic parameters, through the determination of systemic arterial compliance (SAC) and peripheral vascular resistance (PVR), was shown to be useful in the assessment and prognosis of patients with aortic valve disease ${ }^{5,6}$. This work compares the prevalence of diastolic dysfunction (DD) according to the criteria of both these guidelines and its relationship with SAC and PVR, which are parameters that indicate hemodynamic involvement and might establish the prognosis, calculated in a non-invasive manner.

\section{Material and methods}

\section{Population}

Three-hundred and six 40-year-old or older patients who were referred to the authors' center for Doppler echocardiogram performance and who had an ejection fraction $(E F) \geq 50 \%$ were consecutively included. Patients with a history of acute myocardial infarction, sinus tachycardia (heart rate $>110$ beats $/ \mathrm{min}$ ), atrial fibrillation or flutter at the time of the study, permanent pacemaker implanted, or worse than mild heart valve disease were included in the study.

\section{Echocardiographic evaluation}

All echocardiographic studies were carried out with the Philips Affiniti 50 ultrasound equipment. Chamber quantification and function assessment were carried out according to the 2015 ASE/EACVI guidelines recommendations ${ }^{7}$. The types of ventricular hypertrophy were classified according to EACVI new indications ${ }^{8}$.

DD parameters were quantified in apical views. Mitral filling velocities ( $E$ and $A$ peaks) and $E$ peak deceleration time (DTE) were determined with pulsed Doppler, at the level of mitral leaflets distal ends, at mitral valve opening (with an average of three consecutive beats). Using tissue Doppler, lateral and septal (e' and a') mitral annulus velocities were calculated and the corresponding relationships ( $E / A$ and $\left.E / e^{\prime}\right)$ were determined.

Tricuspid regurgitation speed measurement was obtained by continuous Doppler and, using Bernoulli's simplified equation, the right ventriculoatrial pressure gradient was established.

\section{Non-invasive hemodynamic measurements}

All patients underwent non-invasive blood pressure measurement with sphygmomanometer during the procedure. Pulse pressure (PP) was calculated with the following operation: systolic blood pressure minus diastolic blood pressure. Mean blood pressure (MBP) was determined by the product of systolic blood pressure by one-third of PP. SAC was calculated with the following equation ${ }^{9}$ :

$\mathrm{SAC}=$ indexed systolic volume/(PP)

PVR was established using the following formula ${ }^{10}$ : $\mathrm{PVR}=80 \times \mathrm{MBP} /$ cardiac output

\section{DD classification}

To determine DD using ASE/EAE 2009 guidelines, lateral and septal e' values (> 10 and 8 , respectively) were taken in the first instance, together with the left atrium volume $\left(>34 \mathrm{~mL} / \mathrm{m}^{2}\right)$; when these parameters were present, the following parameters were taken into account to determine the degree of DD: E/A ratio, DTE, 
and average e/e' ratio. The parameters had to be positive for the degree of DD to be established, and when the parameters were ambiguous, the degree of DD was regarded as indeterminate.

To establish DD using ASE/EACVI 2016 guidelines, four parameters were used: (a) average E/e' ratio > 14; (b) septal e' ratio < 7 or lateral e' ratio < 10; (c) left atrial volume $>34 \mathrm{~mL} / \mathrm{m}^{2}$; and (d) tricuspid regurgitation velocity $>2.8 \mathrm{~m} / \mathrm{s}$. More than $50 \%$ of the parameters had to be positive, which was possible to attain, for the presence of $D D$ to be determined. If half of the obtained parameters were positive, diastolic function was regarded as indeterminate. To determine the DD grade, the following parameters were used: $E / A$ ratio and $E$ peak velocity. Subsequently, the following parameters were taken into account: (a) left atrial volume $>34 \mathrm{~mL} / \mathrm{m}^{2}$; (b) tricuspid regurgitation velocity $>2.8 \mathrm{~m} / \mathrm{s}$; and (c) average $E / e^{\prime}$ ratio $>14$. If two of the latter parameters were positive, the DD grade was determined; if only two criteria were available, both had to be positive. In case one was positive and the other negative, the DD grade was considered to be indeterminate.

\section{Statistical analysis}

Continuous variables are presented as the mean \pm standard deviation (SD) and categorical variables, as percentages. Agreement between both classifications was determined with the kappa coefficient. The comparisons between normal individuals and DD with the hemodynamic variables were carried out using the rank-sum test; and the comparison between normal, indeterminate function, or DD of the 2016 ASE/EACVI guidelines with the hemodynamics measurements was carried out using a one-way analysis of variance or Kruskal-Wallis test for continuous variables. The Chisquare test or Fisher's exact test, as appropriate, was used to determine categorical variables' differences. The dichotomous variables that were statistically significant for the prediction of SAC $<0.60 \mathrm{~mL} . \mathrm{mmHg}^{-1}$ and PVR $>1400 \mathrm{mmHg} \cdot \mathrm{min}^{-\mathrm{L}^{-1}}$ were subjected to the logistic regression test, for a multivariate analysis. $p=<0.05$ was considered statistically significant. These statistical analyses were carried out with the STATICTIX 8.0, EPI INFO 6.0 $0^{\mathrm{TM}}$, and MedCalc programs.

\section{Results}

Three-hundred and six patients were included in this study, out of which $59.2 \%$ were female, with a mean age of 59.6 years $( \pm 10.4)$ (Table 1). About $85.6 \%$ of
Table 1. Clinical and echocardiographic characteristics of the population

\begin{tabular}{|l|c|}
\hline Variable & Value \\
\hline Age (years) & $59.6( \pm 10.4)$ \\
\hline Female gender (\%) & 59.2 \\
\hline High blood pressure (\%) & 63.4 \\
\hline Diabetes (\%) & 16.3 \\
\hline Dyslipidemia (\%) & 34.3 \\
\hline Body mass index & $29.6( \pm 5.59)$ \\
\hline Obesity (\%) & 39.9 \\
\hline EF (\%) & $65.2( \pm 5.59)$ \\
\hline Left atrial volume (mL/m²) & $35.6( \pm 8.02)$ \\
\hline Myocardial mass index (g/m²) & $102( \pm 29.02)$ \\
\hline End-diastolic volume (mL) & $85.4( \pm 23)$ \\
\hline End-systolic volume (ml) & $30.9( \pm 10.5)$ \\
\hline Eccentric hypertrophy (\%) & 41.8 \\
\hline Concentric hypertrophy (\%) & 10.8 \\
\hline E/A ratio & $1,436.53( \pm 352.81)$ \\
\hline DTE (ms) & $0.95( \pm 0.34)$ \\
\hline Average E/e' ratio & $222( \pm 49.9)$ \\
\hline Tricuspid regurgitation velocity (m/s) & $8.62( \pm 2.9)$ \\
\hline Systolic blood pressure (mmHg) & $2.32( \pm 0.34)$ \\
\hline Diastolic blood pressure (mmHg) & $131.38( \pm 18.87)$ \\
\hline SAC (mL.mmHg-1) & $73.43( \pm 10.1)$ \\
\hline PVR (mmHg.min.L-1) & $0.73( \pm 0.23)$ \\
\hline
\end{tabular}

patients had no symptoms, $2 \%$ had New York Heart Association functional class (FC) I dyspnea, $11.6 \%$ had FC II, and $0.6 \%$ FC III. Of the hypertensive patients, $60.5 \%$ were on antihypertensive medication. Out of them, $51.8 \%$ were treated with one antihypertensive drug, $41 \%$ with two, and $7.2 \%$ with three or more. The feasibility of obtaining all four parameters that determine the presence of DD in 2016 ASE/EACVI guidelines was $59.5 \%$, for three parameters, $40.2 \%$, and in $0.3 \%$, only two parameters were obtained. The parameters that assess DD in ASE/EAE 2009 guidelines were obtained in $99.7 \%$. Tricuspid regurgitation velocity determination was not possible in $41.2 \%$ of cases.

The prevalence of DD, according to ASE/EAE 2009 guidelines, was $32.7 \%$, while according to the algorithm 
Table 2. Agreement between DD criteria (kappa coefficient, 0.56; confidence interval, 0.46-0.66; $p=0.051$ )

\begin{tabular}{|l|c|c|c|}
\hline & \multicolumn{2}{|c|}{$\begin{array}{c}\text { 2009 ASE/EACVI diastolic } \\
\text { dysfunction }\end{array}$} & \\
\hline $\begin{array}{l}2016 \text { ASE/EACVI } \\
\text { diastolic dysfunction }\end{array}$ & Yes & No & \\
\hline Yes & 58 & 12 & $70(22.9 \%)$ \\
\hline No & 42 & 194 & $236(77.1 \%)$ \\
\hline & $100(32.7 \%)$ & $206(67.3 \%)$ & 306 \\
\hline
\end{tabular}

of the 2016 ASE/EACVI guidelines, it was 22.9\% (Fig. 1). In patients with DD, according to ASE/EAE 2009 guidelines, the grades were I, $42 \%$; II, $30 \%$; III, $0 \%$; and indeterminate, $28 \%$. When DD was classified according to ASE/EACVI 2016 guidelines, the grades were I, 17.1\%; II, 44.3\%; III, 1.4\%; and indeterminate, $37.2 \%$.

Agreement between both guidelines' DD criteria was moderate (kappa coefficient, 0.56); of the 100 patients with DD criteria based on the ASE/EAE 2009 guidelines, 42 were reclassified as not having DD with ASE/ EACVI 2016 guidelines criteria (Table 2). Of these 42 patients, $40(95 \%)$ were reclassified as indeterminate, and $2(5 \%)$, with normal diastolic function.

Mean SAC in subjects with DD, according to ASE/ EAE 2009 guidelines, was $0.67( \pm 0.22) \mathrm{mL} \mathrm{mmHg}^{-1}$, and in those with normal diastolic function, it was 0.76 $( \pm 0.20) \mathrm{mL} \cdot \mathrm{mmHg}^{-1}(p=0.0001)$. Patients with $\mathrm{DD}$, according to ASE/EACVI 2016 guidelines, had a mean SAC of $0.67( \pm 0.22) \mathrm{mL} \cdot \mathrm{mmHg}^{-1}$, while in those with normal diastolic function, it was $0.75( \pm 0.24) \mathrm{mL} \mathrm{mmHg}^{-1}$ $(p=0.0007)$. Mean PVR of patients with normal diastolic function, according to the ASE/EAE 2009 guidelines, was $1403( \pm 338) \mathrm{mmHg} \cdot \mathrm{min} \cdot \mathrm{L}^{-1}$, and in those with DD, $1509( \pm 366) \mathrm{mmHg} \cdot \mathrm{min} \cdot \mathrm{L}^{-1}(p=0.005)$. In individuals with preserved diastolic function, according to ASE/EACVI 2016 guidelines, mean PVR was 1412 $( \pm 334) \mathrm{mmHg} \cdot \mathrm{min} . \mathrm{L}^{-1}$, and in those with $\mathrm{DD}$, said parameter was $1523( \pm 390) \mathrm{mmHg} \cdot \mathrm{min} \cdot \mathrm{L}^{-1}(p=0.018)$.

Based on ASE/EACVI 2016 guidelines, indeterminate patients had a lower mean SAC than subjects with normal diastolic function $\left(0.73 \mathrm{~mL} \cdot \mathrm{mmHg}^{-1}\right.$ vs. $0.76 \mathrm{~mL} . \mathrm{mmHg}^{-1}$, respectively) and better profile in comparison with patients with DD $(p=0.005$ for all three groups). The same behavior was shown by PVR, which was $1516 \mathrm{mmHg} \cdot \mathrm{min} . \mathrm{L}^{-1}$ for patients with $\mathrm{DD}$, $1478.41 \mathrm{mmHg} \cdot \mathrm{min} . \mathrm{L}^{-1}$ for indeterminate individuals, and $1385 \mathrm{mmHg} \cdot \mathrm{min} . \mathrm{L}^{-1}$ for patients with normal diastolic function $(p=0.009)$.

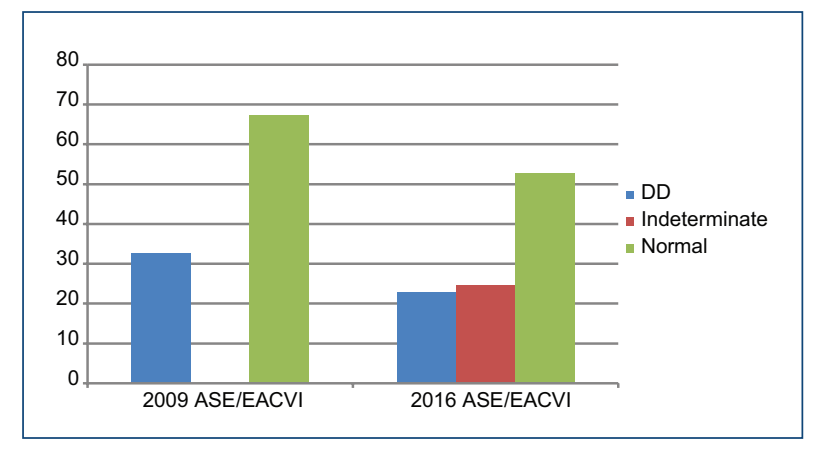

Figure 1. Prevalence of diastolic dysfunction according to the different guidelines.

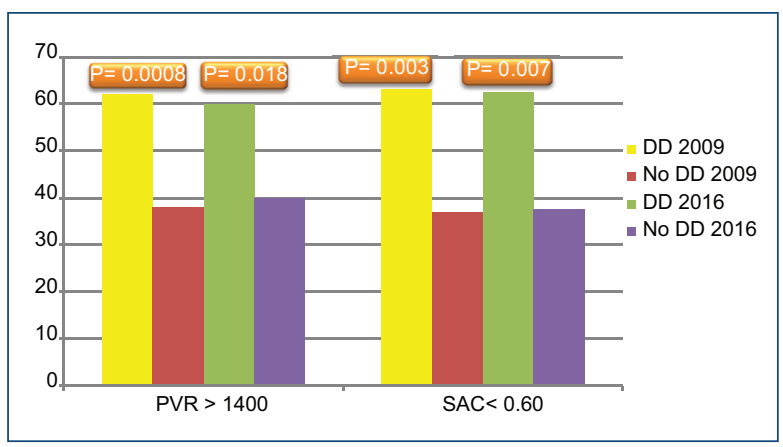

Figure 2. Prevalence of PVR $>1400 \mathrm{mmHg} \cdot \mathrm{min}^{. \mathrm{I}^{-1}}$ and SAC $<0.60 \mathrm{mmHg} \cdot \mathrm{min} . \mathrm{l}^{-1}$ according to the presence or absence of DD.

Among the patients with sufficient criteria for DD, according to both guidelines, a larger number of subjects with PVR > $1400 \mathrm{mmHg} \cdot \mathrm{min} \cdot \mathrm{L}^{-1}$ and SAC $<0.60 \mathrm{~mL} \cdot \mathrm{mmHg}^{-1}$ were found than among patients without sufficient criteria for DD (Fig. 2).

High blood pressure (HBP) ( $p=<0.0001)$, dyslipidemia $(p=0.017)$, obesity $(p=0.015)$, smoking $(p=0.015)$, DD according to ASE/EAE 2009 guidelines ( $p=0.003$ ), and DD according to ASE/EACVI 2016 guidelines $(p=0.009$ ) were found to be predictor variables of $\mathrm{SAC}<0.60 \mathrm{~mL} \cdot \mathrm{mmHg}^{-1}$. In the multivariate analysis, HBP persists as the only predictor variable of $\mathrm{SAC}<0.60 \mathrm{~mL} . \mathrm{mmHg}^{-1}(p=0.0034)$ (Table 3).

$\operatorname{HBP}(p=0.001)$, diabetes mellitus (DM) $(p=0.045)$, DD according to ASE/EAE 2009 guidelines $(p=0.0008)$, and DD according to ASE/EACVI 2016 guidelines $(p=0.013)$ were predictor variables of PVR $>1400 \mathrm{mmHg} \cdot \mathrm{min} \cdot \mathrm{L}^{-1}$. In the logistic regression analysis, DM ( $p=0.0395)$, HBP $(p=0.0111)$, and DD according to ASE/EAE 2009 guidelines $(p=0.0263)$ persist as predictor variables (Table 4). 
Table 3. Logistic regression of predictor variables for $\mathrm{SAC}<0.60 \mathrm{~mL} . \mathrm{mmHg}^{-1}$

\begin{tabular}{|l|c|c|c|}
\hline Variables & Coefficient & Standard error & p \\
\hline Constant & -2.30540 & 0.32239 & 0.0000 \\
\hline Dyslipidemia & 0.31155 & 0.28479 & 0.2740 \\
\hline Obesity & 0.44915 & 0.27653 & 0.1043 \\
\hline HBP & 0.96627 & 0.32952 & 0.0034 \\
\hline Smoking & 0.62080 & 0.40682 & 0.1270 \\
\hline 2009 ASE/EACVI & 0.48730 & 0.34743 & 0.1607 \\
\hline 2016 ASE/EACVI & 0.17517 & 0.37606 & 0.6414 \\
\hline
\end{tabular}

Table 4. Logistic regression of predictor variables for PVR > $1400 \mathrm{mmHg} \cdot \mathrm{min} \cdot \mathrm{L}^{-1}$

\begin{tabular}{|l|c|c|c|}
\hline Variables & Coefficient & Standard error & $\mathbf{p}$ \\
\hline Constant & -0.58261 & 0.20984 & 0.0055 \\
\hline HBP & 0.63987 & 0.25188 & 0.0111 \\
\hline 2009 ASE/EACVI & 0.69768 & 0.31411 & 0.0263 \\
\hline 2016 ASE/EACVI & 0.07684 & 0.35175 & 0.8271 \\
\hline DM & -0.68164 & 0.33102 & 0.0395 \\
\hline
\end{tabular}

\section{Discussion}

Diastolic function evaluation by Doppler echocardiography begins with the measurement of transmitral flow velocities at the level of mitral leaflets distal ends and their changes with age, normality, and different disorders ${ }^{11}$. The marked dependence on loading conditions made it necessary to have other parameters that more accurately reflected the degree of diastolic compromise and the determination of filling pressures ${ }^{12}$. Mitral annular excursion velocity and its quotient with transmitral flow velocity were added to the study of diastolic function ${ }^{13}$. These parameters, together with the left atrial volume measurement and tricuspid regurgitation velocity, emerged as diastolic function core evaluation parameters. Criteria for their use varied from the complexity of the 2009 ASE/EAE guidelines to an attempt at simplification by ASE/EACVI 2016 guidelines.

In this work, a significant decrease $(p \leq 0.0001)$ in the prevalence of DD according to ASE/EAE 2009 criteria was identified $(32.7 \%)$ with regard to the calculations of the 2016 ASE/EACVI guidelines (22.9\%). This prevalence decrease, despite being statistically significant, is of a lower value than that published in the work by Almeida et al. ${ }^{14}$, where the prevalence according to ASE/EAE 2009 guidelines was $38.1 \%$ and to 2016 ASE/ EACVI $1.4 \%$. In the authors' study, agreement between both guidelines was moderate (kappa coefficient = 0.56), which is different from the above-mentioned study, where agreement between both guidelines was poor (kappa coefficient $=0.18$ ). Of note, in the study by Almeida et al., the percentage of feasibility for obtaining all four parameters of ASE/EACVI 2016 guidelines was $98.4 \%$, whereas in the authors' study, it was $59.5 \%$; tricuspid regurgitation velocity was the variable that was less likely to be obtained (58.8\% of patients). This work is consistent with population-based studies that have assessed pulmonary artery systolic pressure, where the feasibility of their calculations, through tricuspid regurgitation measurement, ranges from 62 to $69 \%$.

On the other hand, in a recent study ${ }^{17}$, a higher prevalence and incidence during DD follow-up was identified by the 2016 ASEA/EACVI guidelines in patients with sepsis than with ASE/EAE 2009 guidelines, with not that marked differences both in DD prevalence and incidence between both guidelines, as it occurs in the authors' study, although with antagonistic results; this is probably due to the different clinical context where diastolic assessment was carried out.

Cardiovascular risk factors produce a reduced ability of the arterial wall to adapt to volumes and pressures transmitted from the left ventricle and increase the peripheral resistance (afterload) it has to endure, with a consequent elevation of the left ventricular filling pressures to maintain the cardiac output. Non-invasive hemodynamic parameters (SAC and PVR), which reflect this disturbance, showed altered values in patients with DD according to both studied guidelines, without substantial differences between both. The presence of DD, according to both guidelines, was predictive of SAC $<0.60 \mathrm{~mL} \cdot \mathrm{mmHg}^{-1}$ and PVR $>1400 \mathrm{mmHg} \cdot \mathrm{min}^{\mathrm{L}} \mathrm{L}^{-1}$ in the univariate analysis. Only DD established by the ASE/EAE 2009 guidelines was an independent predictor of PVR $>1400 \mathrm{mmHg} \cdot \mathrm{min} . \mathrm{L}^{-1}$. The authors identified differences in the hemodynamic profiles of patients classified as normal, indeterminate, or DD according to 2016 guidelines, which reveal that individuals considered as indeterminate have a poorer hemodynamic profile than normal patients and better non-invasively assessed hemodynamic status in comparison with those with DD. Recent studies showed the capacity of the 2016 guidelines, in terms of sensitivity and 
specificity, to predict filling pressures elevation, invasively evaluated ${ }^{18}$; in this study, the predictive capacity between both guidelines was not substantially different. This is similar to the authors' study, where both classifications showed predictive capacity for the presence of non-invasively measured hemodynamic alterations, with a slight superiority for the ASE/EAE 2009 guidelines, since the latter were an independent predictor of PVR $>1400 \mathrm{mmHg} \cdot \mathrm{min} \cdot \mathrm{L}^{-1}$.

\section{Conclusion}

ASE/EACVI 2016 guidelines reduce the prevalence of DD in comparison with AS/EAE 2009 guidelines. Both guidelines predict SAC and PVR alteration. The predictive power for the development of hemodynamic alterations, through SAC and PVR non-invasive measurement, it is slightly higher in the ASE/EAE 2009 guidelines in comparison with those of 2016.

\section{Funding}

This research did not receive any specific grant from agencies of the public, commercial, or non-profit sectors.

\section{Conflicts of interest}

The authors declare that they have no conflicts of interest.

\section{Ethical disclosures}

Protection of human and animal subjects. The authors declare that no experiments were performed on humans or animals for this research.

Confidentiality of data. The authors declare that no patient data appear in this article.

Right to privacy and informed consent. The authors declare that no patient data appear in this article.

\section{References}

1. Wan SH, Vogel MW, Chen HH. Pre-clinical diastolic dysfunction. J Am Coll Cardiol. 2014;63:407-16

2. Nagueh SF. Prognostic power of mitral annulus indices of left ventricular diastolic function. J Am Heart Assoc. 2014;3:e001012.

3. Nagueh SF, Smiseth OA, Appleton CP, Byrd BF $3^{\text {rd }}$, Dokainish H, Edvardsen $\mathrm{T}$, et al. Recommendations for the evaluation of left ventricular diastolic function by echocardiography: an update from the American Society of Echocardiography and the European Association of Cardiovascular Imaging. Eur Heart J Cardiovasc Imaging. 2016;17:1321-60.

4. Nagueh SF, Appleton CP, Gillebert TC, Marino PN, Oh JK, Smiseth OA, et al. Recommendations for the evaluation of left ventricular diastolic function by echocardiography. Eur J Echocardiogr. 2008;10:165-93.

5. Briand M, Dumesnil JG, Kadem L, Tongue AG, Rieu R, Garcia D, Pibarot $P$. Reduced systemic arterial compliance impacts significantly LV afterload and functions in aortic stenosis: implications for diagnosis and treatment. J Am Coll Cardiol. 2005;46:291-298.

6. Hachicha Z, Dumesnil JG, Bogaty P, Pibarot P. Paradoxical low flow, low gradient severe aortic stenosis despite preserved ejection fraction is associated with higher afterload and reduced survival. Circulation. 2007;115:2856-2864.

7. Lang R, Badano L, Mor-Avi V, Afilalo J, Armstrong A, Ernand L, et al. Recommendations for cardiac chamber quantification by echocardiography in adults: an update from the American Society of Echocardiography and the European Association of Cardiovascular Imaging. J Am Soc Echocardiogr. 2015;28:1-39.

8. Marwick TH, Gillebert TC, Aurigemma G, Chirinos J, Derumeaux G, Galderisi M, et al. Recommendations on the use of echocardiography in adult hypertension: a report from the European Association of Cardiovascular Imaging (EACVI) and the American Society of Echocardiography (ASE). J Am Soc Echocardiogr. 2015;28:727-54.

9. Chemla D, Hébert J-L, Coirault C. Total arterial compliance estimated by stroke volume-to-aortic pulse pressure ratio in humans. Am J Physiol Heart Circ Physiol. 1998;274:H500-5.

10. Kadem L, Dumesnil JG, Rieu R, Durand LG, García D, Pibarot P. Impact of systemic hypertension on the assessment of aortic stenosis. Heart. 2005;91:354-361.

11. Kuo LC, Quinones MA, Rokey R, Sartori M, Abinader EG, Zoghbi WA. Quantification of atrial contribution to left ventricular filling by pulsed wave Doppler echocardiography and the effect of age in normal and diseased hearts. Am J Cardiol. 1987;59:1174-8.

12. Hurrell DG, Nishimura RA, Ilstrup DM, Appeton CP. Utility of preload alteration in assessment of left ventricular filling pressure by Doppler echocardiography: a simultaneous catheterization d Doppler echocardiographic study. J Am Coll Cardiol. 1997;30:459-67.

13. Ommen SR, Nishimura RA, Appleton CP, Miller FA, Oh JK, Redfield MM, et al. Clinical utility of Doppler echocardiography and tissue Doppler imaging in the estimation of left ventricular filling pressures: a comparative simultaneous Doppler-catheterization study. Circulation. 2000;102:1788-94.

14. Almeida JG, Fontes-Carvalho R, Sampaio F, Ribeiro J, Bettencourt $P$, Flachskampf FA, et al. Impact of the 2016 ASE/EACVI recommendations on the prevalence of diastolic dysfunction in the general population. Eur Heart J Cardiovasc Imaging. 2018;19:380-6.

15. Brittain E, Nwabuo C, Xu M, Gupta D, Hemnes A, Moreira H, et al. Echocardiographic pulmonary artery systolic pressure in the Coronary Artery Risk Development in Young Adults (CARDIA) Study: associations with race and metabolic dysregulation. J Am Heart Assoc. 2017;6:e005111. DOI:10.1161/JAHA.116.005111.

16. Lam C, Borlaug B, Kane G, Enders F, Rodeheffer R, Redfield M. Age-associated increases in pulmonary artery systolic pressure in the general population. Circulation. 2009;119:2663-2670.

17. Clancy D, Scully T, Slama M, Huang S, McLean A, Sam R. Application of updated guidelines on diastolic dysfunction in patients with severe sepsis and septic shock. Ann Intensive Care. 2017; 7:121-130

18. Balaney B, Medvedofsky D, Mediratta A, Singh A, Ciszek B, Kruse E, et al. Invasive validation of the echocardiographic assessment of left ventricular filling pressures using the 2016 diastolic Guidelines: head-to-head comparison with the 2009 Guidelines. J Am Soc Echocardiogr. 2018;31:79-88. 